University of Nebraska - Lincoln

DigitalCommons@University of Nebraska - Lincoln

Craig J. Eckhardt Publications

Published Research - Department of Chemistry

February 1973

\title{
An External Goniometer for Orientation of a Cryostat
}

\author{
N.C. Lockhart \\ University of Nebraska - Lincoln \\ L.F. Nichols \\ University of Nebraska - Lincoln \\ Craig J. Eckhardt \\ University of Nebraska - Lincoln, ceckhardt1@unl.edu
}

Follow this and additional works at: https://digitalcommons.unl.edu/chemistryeckhardt

Part of the Chemistry Commons

Lockhart, N.C.; Nichols, L.F.; and Eckhardt, Craig J., "An External Goniometer for Orientation of a Cryostat" (1973). Craig J. Eckhardt Publications. 40.

https://digitalcommons.unl.edu/chemistryeckhardt/40

This Article is brought to you for free and open access by the Published Research - Department of Chemistry at DigitalCommons@University of Nebraska - Lincoln. It has been accepted for inclusion in Craig J. Eckhardt Publications by an authorized administrator of DigitalCommons@University of Nebraska - Lincoln. 


\title{
An External Goniometer for Orientation of a Cryostat
}

\author{
N. C. Lockhart, L. F. Nichols, and C. J. Eckhardt* \\ Department of Chemistry, University of Nebraska, Lincoln, Nebraska 68508
}

(Received 24 January 1972; and in final form, 22 May 1972)

\begin{abstract}
An economical two-circle orienting external goniometer has been designed and fabricated for an Andonian liquid helium Dewar. The Dewar can be tilted $\pm 30^{\circ}$ from the vertical in two perpendicular directions. The geometrical center of the Dewar's optical cavity moves a maximum of $1 \mathrm{~mm}$ when the cryostat is tilted the full $30^{\circ}$. The basic design involves the rotation of two concentric cylinders riding on bearing surfaces. Two chain belts and gear boxes are used as drive mechanisms.
\end{abstract}

\section{INTRODUCTION}

Experiments on single crystals often require the precise alignment of a crystal face or direction to a laboratory axis. At low temperature, $\sim 4 \mathrm{~K}$, this operation is difficult to perform with a conventional single crystal goniometer mounted inside a cryostat. An alternative solution is to orient the cryostat which contains the single crystal.

A cryostat-cradle assembly has been described by Dyer, ${ }^{1}$ but his design does not provide the fine adjustment often required by single crystal experiments. Heaton and Adam $^{2}$ have constructed a cryostat goniometer using expensive spiroid gears with screw gear drives which are driven by computer controlled stepper motors.

The cryostat goniometer described here is economical, easy to construct, and simple to operate. It was designed for obtaining the specular reflection spectra of single crystals mounted in an Andonian 0-24-250/7M cryostat, but it can be modified easily for other single crystal experiments.

\section{DESIGN AND FABRICATION}

The goniometer consists of two concentric rings, $A$ and $B$ in Fig. 1. Ring A allows rotation around the $y$ axis, and
$\mathrm{B}$ may be rotated around the $x$ axis. The cylinders, $\mathrm{A}$ and $B$, were cast from aluminum and machined to a tolerance of $0.025 \mathrm{~mm}$. The dimensions were dependent upon the size of the cryostat's sample mounting column. The inner cylinder $\mathrm{A}$ is $12.7 \mathrm{~cm}$ in depth with an outside diameter of $25.4 \mathrm{~cm}$ and an inside diameter of $15.24 \mathrm{~cm}$. The insert I holds the cryostat firmly in place. The hole G was bored to a tolerance of $0.025 \mathrm{~mm}$ less than the diameter of the cryostat sample mounting tube to increase the rigidity of the cryostat mount. The rotation about the $y$ axis is accomplished by a chain drive which is threaded in a groove $\mathrm{E}$; the chain is bolted to the groove with two set pins. The groove was cut all the way around the ring at a depth twice the width of the chain. This allowed the chain to be slipped inside when the inner cylinder was mounted inside the outer cylinder. The bearing races are mounted on turned sections $\mathrm{J}$ which were machined to $1.270 \mathrm{~cm}$ depth on the outer front and back surfaces of the A cylinder.

The outer cylinder B has a $35.6 \mathrm{~cm}$ o.d. and a $25.4 \mathrm{~cm}$ i.d.; the depth is $15.90 \mathrm{~cm}$. The cryostat can only be tilted $\pm 30^{\circ}$ from the vertical because further tilting would cause spillage of the cryogenic liquid. The $y$ rotation is made possible by the slot $S$ on top of the $B$ cylinder. On
FIG. 1. Exploded diagram of the external goniometer. A and B-Concentric rotation cylinders; D-idler sprockets; $\mathrm{E}$-drive chain mounting groove; G-cryostat mounting hole; $\mathrm{H}$-turned section; I-cryostat mounting insert; $J$-turned section ; $\mathrm{K}$-idler sprocket mounting slot; $\mathrm{L}$-spindles for rotation around $x$ axis; $M-$ spindle bearing assembly mounting caps; $\mathrm{N}$-spindle bearing assembly; $\mathrm{P}$-torque plate; $\mathrm{Q}$-goniometer mounting arm; $\mathrm{R}-x$ axis rotation gear box; $\mathrm{S}$-goniometer tilt slot; $\mathrm{W}-\boldsymbol{y}$ axis rotation gear box.

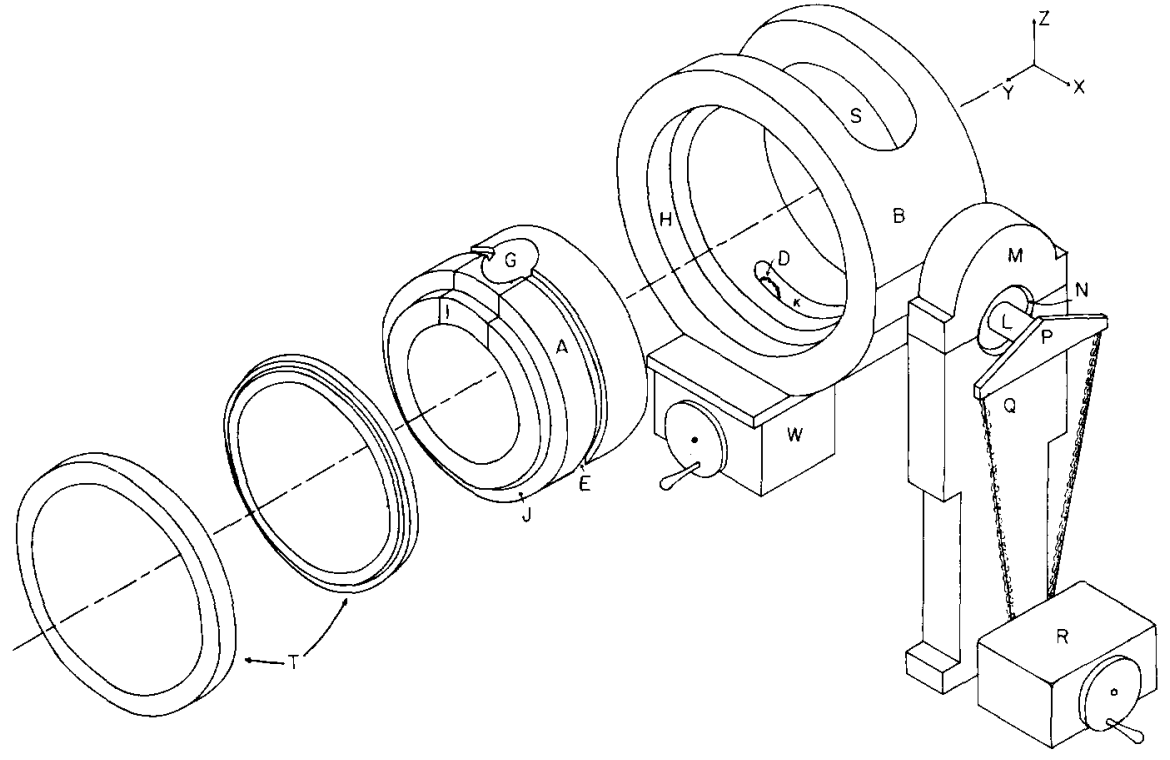

149 


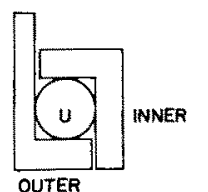

FIG. 2. Cross sectional view of the bearing as sembly. "Inner" and "outer" refer to the position of the bearing races and $U$ designates the balls.

the bottom of this cylinder an additional slot $\mathrm{K}$ allows the drive chain from the inner ring to pass to the gear box $W$. Since binding of the drive chain must be avoided, two idler sprockets $D$ are mounted on rods in the $\mathrm{K}$ slot. These rods fit into the notches which are perpendicular to the slot $\mathrm{K}$. Each bearing race is mounted on a turned section $H$, one on the front and one at the back of the B cylinder. The matching race fits the turned section J of the A cylinder. These races $\mathrm{T}$ were turned from cold steel with a tolerance of $0.008 \mathrm{~mm}$ and were $1.27 \mathrm{~cm}$ thick to give sufficient support for the assembly. When assembled, the races overlap as shown in Fig. 2. The balls are $0.7938 \mathrm{~cm}$ in diameter.

To maintain a constant center of rotation the spindles $L$ must intersect the common center of the cylinders $A$ and $\mathrm{B}$ and also be perpendicular to $\mathrm{Y}$. The torque plate driving the spindle shown is $1.27 \mathrm{~cm}$ thick. The center of the cylinder assembly is $51 \mathrm{~cm}$ above the lowest part clearing the gear box. The over-all dimensions of the arms, when assembled, are $58.5 \times 17.8 \times 5.1 \mathrm{~cm}$. The arms are bolted directly to a base of $5.1 \mathrm{~cm}$ thick aluminum plate.

The gear boxes chosen were Boston Gear model XL-166 with ratio 900:1 for $\mathrm{W}$ ( $y$ axis) and $600: 1$ for $\mathrm{R}$ ( $x$ axis). Each drive chain must have adequate tension to prevent vibration of the cryostat.

The sample mounting column is constructed of thin walled stainless steel which cannot support the mass of the cryosiat. Therefore, the mounting platform, shown in Fig. 3, attaches the cryostat firmly to the inner cylinder with the use of spacers mounted to the front and back faces of the inner cylinder. The top plate $V$ is bolted directly to the base of the cryostat. The completed goniometer assembly is shown in Fig. 4.

\section{INSTRUMENTAL CHARACTERISTICS}

The crystal mounting rod of the cryostat can be rotated $360^{\circ}$ about its axis and translated $\pm 2.54 \mathrm{~cm}$ along the $z$

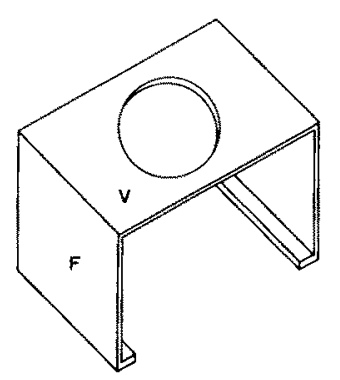

Fig. 3. Cryostat mounting platform. F-Goniometer mounting plates; Vcryostat mounting plate.

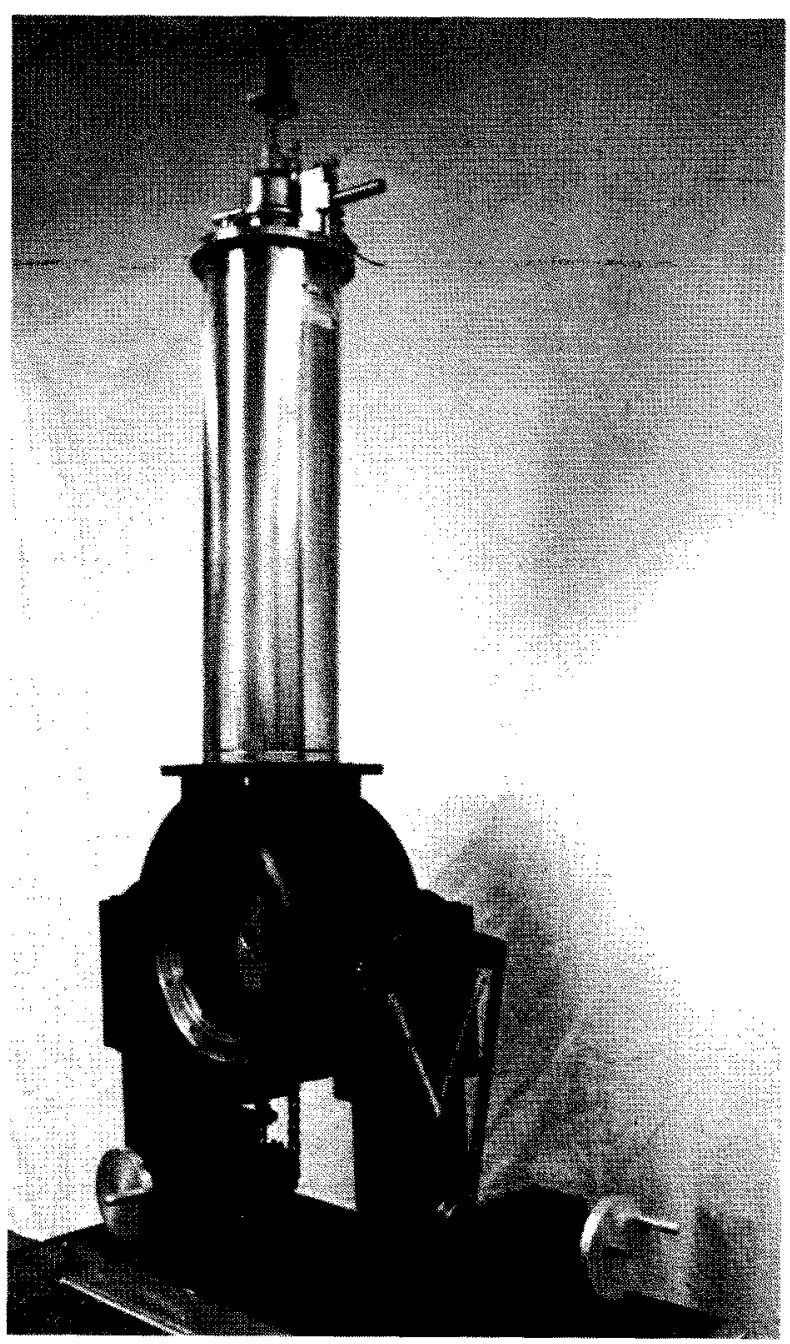

Fig. 4. Photograph of external goniometer with mounted Andonian cryostat.

direction. These motions combined with those of the goniometer allow three rotations and one translation. A rotation around the vertical direction can be obtained after mounting the entire assembly on a rotary table.

To measure the displacement of the center of the cryostat, a coordinate grid lying in the $x z$ plane was attached to the sample mounting rod of the cryostat. The grid was observed through a Gaertner cathetometer whose optical axis was colinear with the $y$ axis while the cryostat was tilted about the $x$ or $y$ axis. Under rotation about the $y$ axis, the center was found to translate a maximum of $\pm 0.4 \mathrm{~mm}$. This motion can be resolved into $x^{\prime}$ and $y^{\prime}$ translations. The primes designate fixed coordinates. The $x^{\prime}$ axis component is corrected with the use of an $x^{\prime}$ direction translation table. The small $z^{\prime}$ axis component is easily corrected by using the vertical translation of the cryostat mounting rod. Rotation about the $x^{\prime}$ axis gave a maximum translation of $\pm 1.0 \mathrm{~mm}$ which may be resolved 
into components along the $y^{\prime}$ and $z^{\prime}$ axes. The $z^{\prime}$ axis can be adjusted as just described while the displacement simply changes the focus of the optical system. Of course, it could also be corrected by means of a $y^{\prime}$ axis translation table.

Considering the large masses and the large torques involved in this system, these small changes are quite satisfactory. The device is economical (parts cost less than $\$ 500$ ), easily fabricated, and may be readily modified for use with other experiments on single crystals at low temperatures.

\section{ACKNOWLEDGMENTS}

The authors thank M. F. Adam for providing plans of his computer controlled cryostat goniometer. The assistance of the Department of Mechanical Engineering of the University of Nebraska is greatly appreciated. The support of the University of Nebraska Research Council is gratefully acknowledged.

* Author to whom correspondence should be addressed. 1 R. H. Dyer, I. Lefkowitz, and P. Martel, Rev. Sci. Instrum. 41, 61 (1970).

${ }^{2}$ M. F. Adam (private communication).

\title{
Reaction Rate Analysis by Gas Evolution: A Constant Volume Variable Pressure Kinetic Apparatus
}

\author{
J. W. TimberLakE* \\ Department of Chemistry, Louisiana State University, New Orleans, Louisiana 70122 \\ AND \\ J. C. MARTIN \\ Department of Chemistry, University of Illinois, Urbana, Illinois 61801
}

(Received 28 February 1972; and in final form, 7 June 1972)

\begin{abstract}
An automatically recording constant volume variable pressure apparatus for measurement of reaction kinetics is described. This instrument has been found to be useful for following rates of reactions in solution that proceed with an increase in pressure of the gas phase over the reaction solution.
\end{abstract}

A standard method for determining solution kinetics of compounds that give gaseous products is to measure the amount of gas evolved at constant pressure as a function of the amount of liquid displaced from a volumetric buret. Alternatively, it is possible to monitor the change in pressure at constant volume. We describe here an instrument suited for such measurements that offers several advantages. The constant volume method makes it unnecessary to know the partial pressure of solvent over the reaction since the volume does not change. This instrument records pressure automatically and continuously, thus offering a greater number of data points and freeing the operator from taking individual readings. The sample size can be varied over a wide range and full scale recorder response still be achieved by a simple attenuator adjustment. We have analyzed kinetic runs for substrates in concentration ranges between 0.1 and $0.01 M$ with samples as small as $15 \mathrm{mg}$. Good precision for rate constants determined from data showing total pressure changes of $0.1 \mathrm{~atm}$ are possible and pressure changes as small as $10 \mu \mathrm{Hg}$ can be detected. Errors in rate constants as indicated by least squares treatment are less than $1 \%$ and reproducibility is generally observed within this limit.
We have used this method for analysis of the decomposition of a number of azoalkanes which thermally evolve nitrogen in a first order process, although, in theory, any reaction which generates products $\left(\mathrm{N}_{2}, \mathrm{CO}, \mathrm{CO}_{2}, \mathrm{SO}_{2}\right.$, hydrocarbons, etc.) with large vapor pressures could be analyzed.

Reactions with half-lives varying from $3 \min$ to $10 \mathrm{~h}$ have been followed over a temperature range of $40-220^{\circ} \mathrm{C}$. No deviations from first order rate dependence were observed for temperatures up to $20^{\circ}$ below the boiling point of the solvent (toluene, cumene, decalin, or diphenyl ether). Control of the constant temperature bath to $\pm 0.05^{\circ}$ gave pressure-time plots with no apparent fluctuation attributable to changes in vapor pressure with temperature. The small standard deviations $(<1 \%)$ of the experimentally determined rate constants provide experimental evidence that this level of temperature control, which is attainable by most commercially available temperature controllers, is adequate for this application.

The apparatus is simple to construct and can be assembled from readily available laboratory equipment with the aid of a glassblower. Figs. 1 and 2 shown below are representations of the apparatus and of its electrical schematic. 